\title{
Methyl Siloxanes in Environmental Matrices around a Siloxane Production Facility, and Their Distribution and Elimination in Plasma of Exposed Population
}

\author{
Lin $\mathrm{Xu},{ }^{\dagger}$ Yali Shi, ${ }^{\dagger}$ Thanh Wang, ${ }^{\dagger}$ Zhirong Dong, ${ }^{\ddagger}$ Weiping Su, ${ }^{\ddagger}$ and Yaqi Cai ${ }^{\dagger}, *$ \\ ${ }^{\dagger}$ State Key Laboratory of Environmental Chemistry and Ecotoxicology, Research Center for Eco-Environmental Sciences, Chinese \\ Academy of Sciences, Beijing 100085, People's Republic of China \\ ${ }^{\ddagger}$ Clinical Laboratory of Yantai Municipal Laiyang Central Hospital, Shandong Province, 265201, People's Republic of China
}

\section{Supporting Information}

ABSTRACT: In this study, we systematically investigated methyl siloxanes (D4-D6, L3-L16) exposure to workers from and residents living near a siloxanes manufacturing facility by measuring their concentrations in both environmental matrices (air, dust/soil, $n=62$ ) and human plasma samples ( $n$ $=201$ ). For the seventeen target compounds, the average concentrations in indoor matrixes from six workshops of the facility ranged from $0.6 \mu \mathrm{g} / \mathrm{m}^{3}$ to $2.7 \mathrm{mg} / \mathrm{m}^{3}$ in air samples and from $0.36 \mu \mathrm{g} / \mathrm{g}$ to $1.16 \mathrm{mg} / \mathrm{g}$ in dust samples, which were $3-5$ orders of magnitudes higher than those levels at the reference zone. In plasma samples from the current workers in six workshops and residents living near the facility, the average

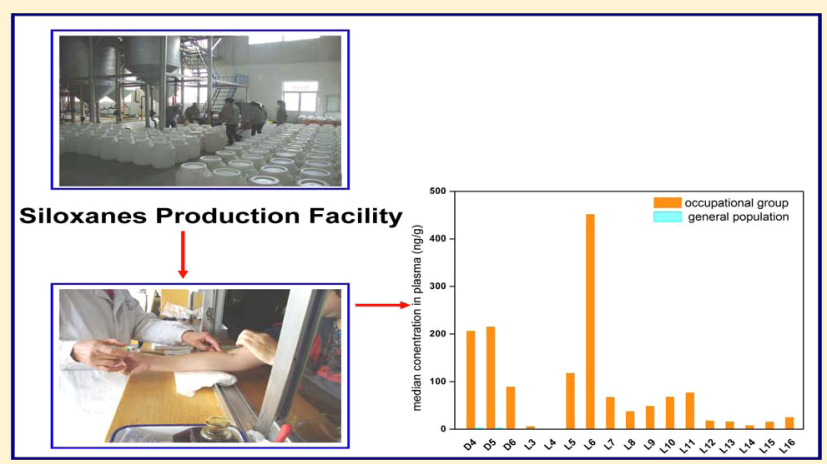
concentrations of methyl siloxanes were 5.61-451 and 4.56-

$13.5 \mathrm{ng} / \mathrm{g}$, respectively, which were 1-2 magnitudes higher than those in the reference group. Plasma methyl siloxanes concentrations of people from different workshops were positively correlated with their exposure levels, indicating that high occupational exposure in siloxane production process elevated human plasma concentrations. However, there was no significant correlation between human plasma concentrations with their duration of occupation. These methyl siloxanes were eliminated from human plasma with half-lives ranging from 2.34 to 9.64 days, which increased with the increasing number of Si-O bonds for most analogues.

\section{INTRODUCTION}

Methyl siloxanes have been widely used for several decades in industrial processes and consumer products such as cosmetics, household cleaning products and health- care products, ${ }^{1-3}$ due to low surface tension, high thermal stability and lubricating properties. Because of their wide use, these methyl siloxanes are present in many environmental matrices. ${ }^{4-7}$ Furthermore, some methyl siloxanes bioaccumulate in some biota, such as fish and ragworm, ${ }^{8}$ due to their high octanol-water partition coefficients. Recently, the toxicity of methyl siloxanes to the reproductive, immune, and nervous systems of animals and humans has become a public health concern. ${ }^{9-11}$

Methyl siloxanes are present in air, dust, and soil samples from places with human activities, including sites close to siloxanes production/use facilities, indoor and outdoor of buildings in cities, and field in rural areas, ${ }^{12-15}$ where human exposure to methyl siloxanes via inhalation and ingestion is likely. However, in order to better evaluate their exposure sources and potential adverse health effects, examination of biological matrixes such as human plasma/blood may be necessary. Several groups have measured methyl siloxane concentrations in human plasma in controlled human exposures, such as the reports on octamethylcyclotetrasiloxane (D4) and decamethylcyclopentasiloxane (D5) concentrations in plasma after $1-\mathrm{h}$ exposures via inhalation $(122$ and $153 \mu \mathrm{g} / \mathrm{L}$ for D4 and D5, respectively.) ${ }^{16,17}$ However, to our knowledge, there are no reports on methyl siloxane concentrations in the plasma of general or highly exposed populations in P.R. China or other countries. Siloxane production facilities are one of the major pollution sources of methyl siloxanes, ${ }^{12}$ where workers could have high risks of occupational exposure to these compounds. These siloxane production facilities can provide a good test area for looking at methyl siloxanes exposure, distribution, and elimination in plasma of exposed population, and then would further provide valuable data in the research on human health effect of these compounds.

The goals of the present study are (1) to investigate the occurrence and behavior of methyl siloxanes in environmental matrixes (air, dust, and soil) within and in proximity of a

Received: June 10, 2012

Revised: October 9, 2012

Accepted: October 15, 2012

Published: October 15, 2012 

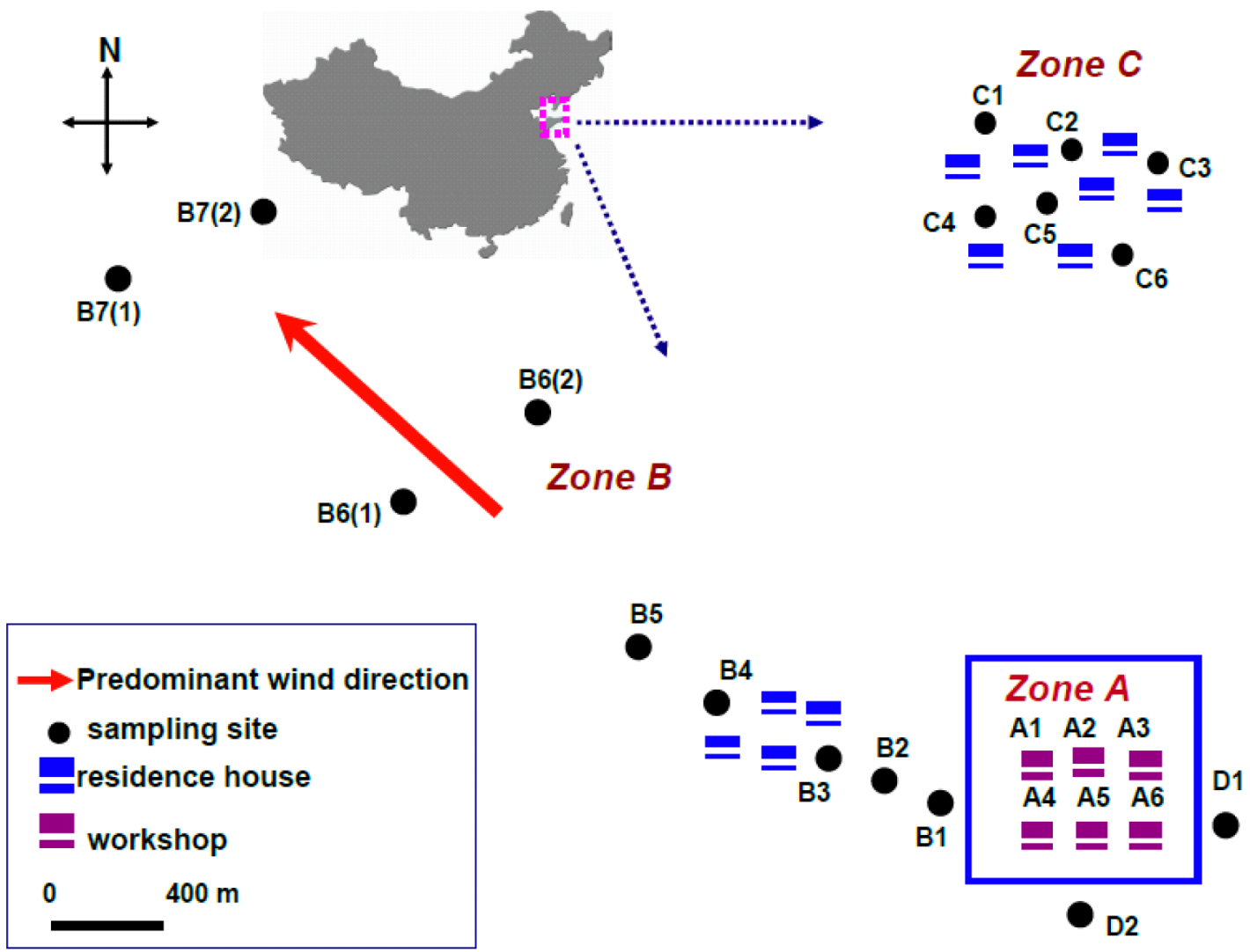

Figure 1. Sampling locations in three zones (A, B, and C) of the studied area.

siloxanes production facility, (2) to estimate the level of human exposure to methyl siloxanes in the studied area, and the influence of both exposure level (daily intake) and exposure time (years worked) on plasma methyl siloxanes concentrations of current worker and residents in the studied area, and (3) to estimate population based half-lives of methyl siloxanes in human plasma by surveying the temporal trends of plasma methyl siloxanes concentrations of former workers after leaving the production facility. To the best of our knowledge, this paper is the first regional study to systematically estimate the potential for methyl siloxane exposures and assess plasma concentrations in a relatively highly exposed population.

\section{MATERIALS AND METHODS}

2.1. Sampling. The studied area is located in the east of Shandong Province, P.R. China. In this area, the predominant wind direction is southeastern between April and October, while northwestern between November and March. We divided this area into three zones (Figure 1). The siloxane production facility is located in Zone A, and has been producing cyclic and linear methyl siloxanes products for more than 15 years, with an annual yield of about 10000 tonnes. The main production processes involves acid-catalytically cracking of raw materials (waste silicone rubber) to mixed products of methyl siloxanes analogues, and rectifying to obtain the end monomers. Six workshops of the facility were sampled, including a raw material storage workshop (A1), cracking and rectification workshops (A2 A5), and product storage workshop (A6). Zone B is downwind of Zone A during April to October. In this zone, a residential community with a population of about 2000 is located about $400-1000 \mathrm{~m}$ from the facility. Zone C, selected as a reference zone, is located at the perpendicular wind direction of Zone A (about $15 \mathrm{~km}$ away). Zone C hosts a residential community with a population of 100000 . Plasma $(n$ $=201)$, air $(n=35)$, dust $(n=13)$, and soil $(n=14)$ samples were collected during August to October, 2011.

2.1.1. Plasma Samples. In August 2011, 72 current workers (61 males and 11 females) from six workshops of the facility were invited to participate in the study voluntarily. In Zone B, 14 individuals (10 males and 4 females) were invited. In addition, 58 (49 males and 9 females) participants from Zone C were invited to serve as a reference group for the assessment of background siloxanes exposure in the region. To investigate the elimination rates of methyl siloxanes in plasma, 57 plasma samples were collected from 32 former workers (all male), who had worked in the same workshop (A3) in the facility for 1-10 years and had resigned for 3-320 days. In Aug 24, 2011, plasma samples were collected from each of the 32 formers and in Oct 2, 2011, 25 out of the same 32 former workers were invited back to provide a second plasma sample. The participants all gave their informed consent documents before the study. Each participant from the three zones, receiving 300 RMB (about 46 USD) as compensation, completed a questionnaire providing auxiliary information such as age, daily working hours, years worked, and days since leaving the facility (Supporting Information, Table S1). The sampling events were approved by the local municipal Center for Disease Control and Prevention (CDC), and Laiyang Central Hospital helped us to perform these events, the institutional review board from which we also got a written consent.

2.1.2. Air Samples. In each of the six workshops (A1-A6), two indoor air samples were collected. Outdoor air sampling sites in Zone B were selected to investigate the potential emission points and pollution pathways. B1-B7 (for both B6 


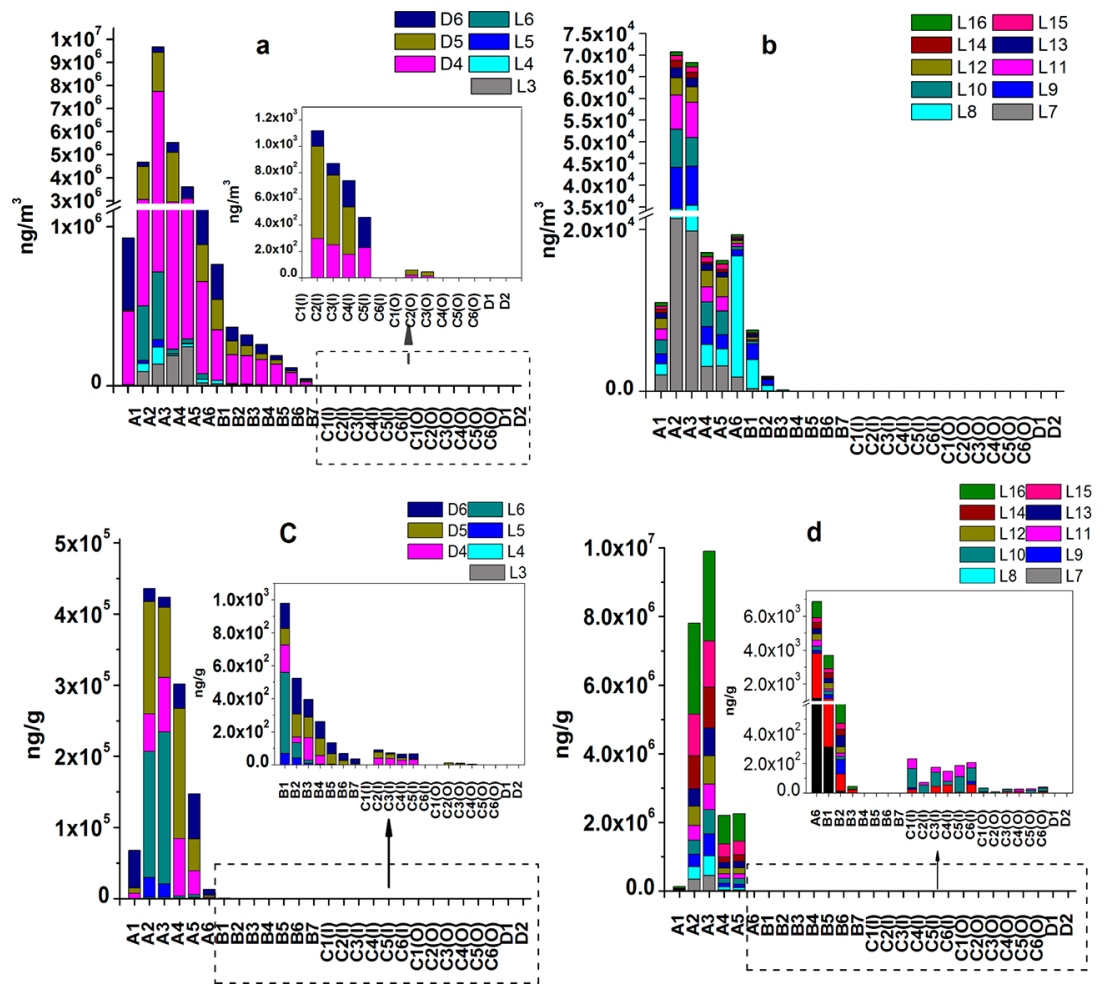

Figure 2. Methyl siloxanes concentrations in air samples ( $a$ and $b$ ) and dust/soil samples ( $c$ and $d$ ) from the three zones.

and B7, two horizontal parallel sites were selected) are located at predominant downwind direction of the facility, while D1 and D2 are at the upwind directions. Air samples of both outdoor and indoor residential houses were collected from C1-C6 sites in Zone C. Air samples were collected using solid phase extraction cartridges as previously reported with minor modifications, ${ }^{18}$ which are described in the Supporting Information.

2.1.3. Dust/Soil Samples. Soil samples were collected from B1-B7, C1-C6, D1, and D2. Each soil sample (about 5g) was collected using a steel syringe (made with a thin steel tube) and quickly ejected into a glass container via squeezing the syringe plunger. The container was filled without headspace and sealed. Dust samples from floor surfaces both inside the six workshops $(\mathrm{A} 1-\mathrm{A} 6)$ and in Zone $\mathrm{C}(\mathrm{C} 1-\mathrm{C} 6)$ were vacuumed, collected using brushes, transferred into glass containers without headspace, and then sealed, respectively. Collected dust and soil samples were stored at $-18^{\circ} \mathrm{C}$, and were pretreated and analyzed as soon as possible.

2.2. Standards and Chemicals. Cyclic siloxane standards (D4, D5, D6, purity >98\%), linear siloxane standards [L3, L4, polydimethylsiloxane mixture (PDMS, L5-L16, which mass profiles were shown in Supporting Information), purity $>98 \%$ )], and tetrakis (trimethylsilyoxy) silane (M4Q purity 97\%) were purchased from Sigma-Aldrich (St. Louis, MO, U.S.). Methanol, ethyl acetate, and $n$-hexane were purchased from Fisher Scientific (Fair Lawn, New Jersey, U.S.).

2.3. Quality Assurance/Quality Control (QA/QC). Pretreatment for plasma, air, and dust/soil samples, instrumental analysis, are described in detail in the Supporting Information.

Due to wide spead use of siloxanes and broad distribution in environment matrices, consumer products, and laboratory products, precautions were taken during sample collection, pretreatment, and analysis: (1) Laboratory personnel participating in this study were forbidden to use any cosmetic products; (2) No sampling or storage device during field collection was made of silica gel; (3) During GC/MS analysis (especially for cyclic methyls siloxanes), low injector port temperature $\left(200^{\circ} \mathrm{C}\right.$ ) and low-bleed capillary columns (HP$5 \mathrm{MS}$ ) were selected to minimize siloxane bleeding from inlet septum and capillary columns; 4) During sampling events, field blanks were collected to assess potential ambient contamination.

Despite the careful precautions, compounds D4, D5, and D6 were detected in laboratory blanks of plasma $(0.06-0.3 \mathrm{ng} / \mathrm{g})$, soil/dust $(0.2-0.5 \mathrm{ng} / \mathrm{g})$, and air samples $\left(0.07-0.1 \mathrm{ng} / \mathrm{m}^{3}\right)$, respectively. Therefore, for concentrations of D4, D5, and D6 reported in the present study, laboratory blank values have been subtracted. For these three compounds, after laboratory blank subtraction, limits of quantitation (LOQs) were determined as 10 times the standard deviation of the laboratory blank signals $(n=7)$. For L3-L16, which were not detectable in laboratory blanks, LOQs were determined as 10 times the standard deviation of signals of laboratory blank samples $(n=7)$ spiked with target compounds at low concentrations. LOQs of seventeen compounds were $0.4-1.0 \mathrm{ng} / \mathrm{g}$ for plasma, $0.5-1.0$ $\mathrm{ng} / \mathrm{g}$ for dust/soil, and $0.14-0.36 \mathrm{ng} / \mathrm{m}^{3}$ for air samples $(24 \mathrm{~h}$ sampling), respectively. Recoveries for plasma, dust/soil, and air samples were $89-95 \%, 81-94 \%$, and $86-92 \%$, respectively. All peak areas of field blanks for plasma, dust/soil, and air samples during sampling events were less than $5 \%$ of their LOQs. Detailed information of QA/QC was described in the Supporting Information.

\section{RESULTS AND DISCUSSION}

3.1. Methyl Siloxanes in Environment around the Production Facility. 3.1.1. Air Samples. All seventeen cyclic 
(D4-D6) and linear (L3-L16) methyl siloxanes were detected in indoor air samples from the facility (Figure 2a,b), with $100 \%$ of detection frequencies (df). Average concentrations of cyclic compounds in six workshops ranged from $34 \mu \mathrm{g} / \mathrm{m}^{3}$ (D6) to $2.7 \mathrm{mg} / \mathrm{m}^{3}$ (D4), which were about $1-3$ orders of magnitudes higher than those at relatively high exposure areas in previous studies, such as in outdoor air samples close to siloxanes production and use facilities in European countries (less than 0.1 to $174 \mu \mathrm{g} / \mathrm{m}^{3}$ for D4, and less than 0.1 to $20 \mu \mathrm{g} / \mathrm{m}^{3}$ for D5), and indoor air of commercial buildings in U.S. (2.5-10 $\mu \mathrm{g} / \mathrm{m}^{3}$ for $\mathrm{D} 4,7.0-39.6 \mu \mathrm{g} / \mathrm{m}^{3}$ for D5). ${ }^{12-14}$ The vapor pressure of linear methyl siloxanes are lower than cyclic ones with the same number of $\mathrm{Si}-\mathrm{O}$ bones, ${ }^{19,20}$ and decreases with increasing number of $\mathrm{Si}-\mathrm{O}$ bones. These physical properties may explain the discrepancy between production and exposure. While the production volume of linear siloxanes was about 70 times higher than cyclic products in this facility, air concentrations of L3-L16 were 1-5 orders of magnitudes lower than D4-D6 in each of six workshops (Figure 2a). Average concentrations of volatile linear compounds (L3-L6) from the six workshops ranged from $1.2(\mathrm{~L} 5)-14.3(\mathrm{~L} 6) \mu \mathrm{g} / \mathrm{m}^{3}$. L7-L16 are not likely to be found in atmosphere due to their low volatilities. However, due to high volume storage in this facility and accelerated volatilization under high temperature (about 180-200 ${ }^{\circ} \mathrm{C}$ ) from the reaction kettles in the production process, L7-L16 were detected in all indoor air samples at the facility with average concentrations ranging from 0.6 (L16) to $8.9 \mu \mathrm{g} / \mathrm{m}^{3}$ (L7). With the exception of $\mathrm{L} 6$ and $\mathrm{L} 15$, average concentrations of $\mathrm{L} 3-\mathrm{L} 16$ in six workshops decreased with the increasing number of $\mathrm{Si}-\mathrm{O}$ bonds (SI Figure S1a), a trend similar to their volatilities.

The manufacturing facility follows emission policies similar to other siloxanes facilities in P.R. China. The wastewater, waste residue, and majority of waste gas were treated using conventional procedures before emission to the nearby environment. However, there were no procedures to control siloxane emission into the atmosphere around the sites. Methyl siloxanes (especially volatiles) could be released from the facility into the ambient air. Figure $2 \mathrm{a}, \mathrm{b}$ also shows the spatial distribution of methyl siloxanes in air of Zone B. At the downwind direction, total concentrations of the seven volatile methyl siloxanes ( $\Sigma$ VMSs), including D4-D6 and L3-L6, in air samples decreased in an exponential trend $\left(R^{2}=0.90, p<\right.$ $0.05)$ with the increase of distance from the studied facility (sites B1-B7). Relative to sites close to the facility (B1, 100 m), the concentrations of $\Sigma$ VMSs at site $5000 \mathrm{~m}$ (B7) away from the facility were about $5.9 \%$. Compared with VMSs, the total concentrations of semivolatile methyl siloxanes ( $\Sigma$ SVMSs), including L7-L16, showed more rapid decrease along the downwind direction. The $\Sigma$ SVMS at B3 (400 m away from the manufacturing facility) declined to a mere $3 \%$ of the level at site B1. Furthermore, among the seven VMSs, cyclic compounds decreased slower than linear ones: total concentrations of $\mathrm{D} 4-\mathrm{D} 6$ at $\mathrm{B} 7$ were about $6 \%$ of those at $\mathrm{B} 1$, while concentrations of L3-L6 at B7 were only $1 \%$ of those at B1. The volatile cyclic methyl siloxanes might be more prone to long-range atmospheric transport due to high volatility, consistent with results from a previous study. ${ }^{18}$

Linear methyl siloxanes were not found in any indoor or outdoor air sample from the reference area (Zone C). Cyclic compounds were detected (Figure $2 \mathrm{a}$ ) in indoor air samples from six sampling sites of Zone $\mathrm{C}$, with concentrations ranging from 0.18 to $0.31 \mu \mathrm{g} / \mathrm{m}^{3}$ ( $\left.\mathrm{df}=67 \%\right), 0.36-0.71 \mu \mathrm{g} / \mathrm{m}^{3}$ ( $\mathrm{df}=$
$50 \%$ ), and $0.09-0.24 \mu \mathrm{g} / \mathrm{m}^{3}(\mathrm{df}=67 \%)$ for $\mathrm{D} 4, \mathrm{D} 5$, and $\mathrm{D} 6$, respectively, about 3-4 orders of magnitudes lower than those in the studied facility. Compared with the concentrations of D4, D5, and D6 found in homes of Sweden (0.16-51.2, 0.5-79.4, and $0.6-164 \mu \mathrm{g} / \mathrm{m}^{3}$, respectively), ${ }^{15}$ indoor air concentrations of the three compounds in Zone $\mathrm{C}$ were relatively lower. As cyclic methyl siloxanes in residential air are mainly from the use of personal care and household products, the lower concentrations in Zone $\mathrm{C}$ may indicate the low consumption rate of personal care and household products in this area. Among six outdoor air samples of Zone C, only D4 and D5 were detectable in two samples (Figure 2a), with the concentration in the range of $14-22 \mathrm{ng} / \mathrm{m}^{3}$, and $32-38 \mathrm{ng} /$ $\mathrm{m}^{3}$, respectively. In general, outdoor air concentrations of cyclic siloxanes were one order of magnitudes lower than those of in indoor air, highlighting the dominance of the indoor exposure pathway in residential area.

3.1.2. Dust and Soil Samples. With the exception of L3 (df $=67 \%)$ and $\mathrm{L} 4(\mathrm{df}=83 \%)$, linear siloxanes were detected in all dust samples of the six workshops (Figure $2 \mathrm{c}, \mathrm{d}$ ). In contrast to results of air samples, average concentrations of L3 (360 ng/g) to $\mathrm{L} 16(1.16 \mathrm{mg} / \mathrm{g})$ in dust samples from the six workshops (Zone A) increased with the increasing number of $\mathrm{Si}-\mathrm{O}$ bonds (SI Figure S1b), mainly due to the decreasing of volatilities and increasing of adsorption abilities in dust. Average concentrations of the three cyclic siloxanes $(\mathrm{df}=100 \%)$ in the six workshops ranged from 32.0 (D6) to 82.2 (D5) $\mu \mathrm{g} / \mathrm{g}$, which were 1-2 orders of magnitudes lower than most linear compounds (L7-L16), likely due to their high vapor pressure and smaller production volume. As noted with the air samples, the concentrations of methyl siloxanes in soil decreased along the downwind direction in Zone B (Figure 2c,d).

In the reference area (Zone $\mathrm{C}$ ), more target compounds were detectable in indoor dust samples than those in indoor air samples (Figure 2c,d), with average concentrations of $23.3 \mathrm{ng} / \mathrm{g}$ $(\mathrm{df}=67 \%), 20.0 \mathrm{ng} / \mathrm{g}(\mathrm{df}=67 \%), 19.0 \mathrm{ng} / \mathrm{g}(\mathrm{df}=67 \%), 31.7$ $\mathrm{ng} / \mathrm{g}(\mathrm{df}=83 \%), 17 \mathrm{ng} / \mathrm{g}(\mathrm{df}=33 \%), 83.3 \mathrm{ng} / \mathrm{g}(\mathrm{df}=100 \%)$, and $49.8 \mathrm{ng} / \mathrm{g}(\mathrm{df}=100 \%)$ for D4, D5, D6, L8, L9, L10, and L11, respectively. Compared with a previous report on methyl siloxane concentrations in indoor dust from living environments in P.R. China, ${ }^{21}$ cyclic methyl siloxanes (D4-D6) in indoor dust samples from residential houses of Zone $C$ had comparable concentrations, while linear compounds (L8-L11) in this area had lower concentrations, a trend that may be due to different consumption patterns of personal care and household products in different areas. In soil samples from Zone $\mathrm{C}$, average concentrations of detectable methyl siloxanes (D5, D6, L8, L9, L10, and L11) were $6.7 \mathrm{ng} / \mathrm{g}(\mathrm{df}=50 \%), 5.0$ $\mathrm{ng} / \mathrm{g}(\mathrm{df}=17 \%), 9.5 \mathrm{ng} / \mathrm{g}(\mathrm{df}=67 \%), 3.0 \mathrm{ng} / \mathrm{g}(\mathrm{df}=33 \%)$, $17.8 \mathrm{ng} / \mathrm{g}(\mathrm{df}=83 \%), 11 \mathrm{ng} / \mathrm{g}(\mathrm{df}=50 \%)$, respectively. In sampling sites of the three zones, indoor dust concentrations of most target compounds (except for L5 and L8) had moderate positive correlations with their indoor air concentrations $\left(R^{2}=\right.$ $0.62-0.99, p<0.05$, SI Table S6), while no significant relation was found between outdoor soil concentrations and outdoor air concentrations. These results indicated that air-dust exchange could play an important role in the spatial distribution of methyl siloxanes in the indoor environment.

3.2. Human Exposure of Methyl Siloxanes via Inhalation and Ingestion. Concentrations of siloxanes in both dust/soil and air samples were used to calculate the human exposure (daily intake) in the three zones. The dust/soil 


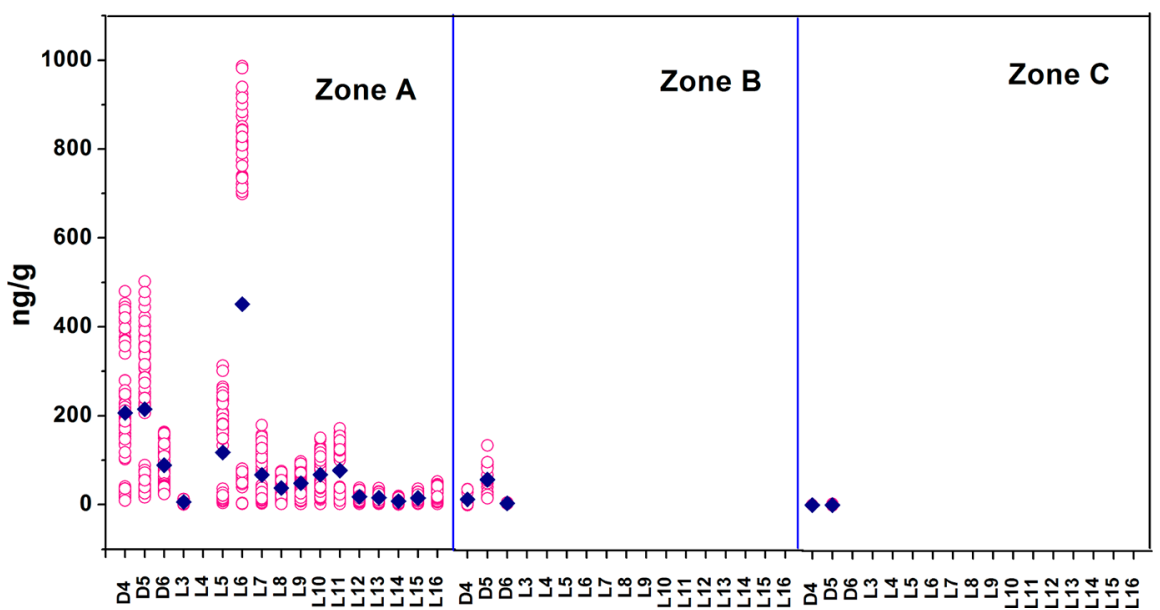

Figure 3. Methyl siloxanes concentrations of plasma samples provided by current workers $(n=72)$ from the production facility (Zone A), residents $(n=14)$ from Zone B (B), and reference group $(n=58$, Zone C): pink "O" represents concentration of individual sample, while blue " $\$$ " represents average concentration.

ingestion rate $\left(E_{\text {ingest }} \mathrm{ng} /\right.$ day) was calculated using the following equation:

$$
E_{\text {Ingest }}=C_{\text {dust } / \text { soil }} \times Q_{\text {dust } / \text { soil }} \times F_{\text {uptake }}
$$

where $C_{\text {dust }}$ represents the siloxane concentration in dust/soil (ng/g), and $Q_{\text {dust/soil }}$ represents the dust ingestion rate (g/day). A high exposure scenario based on EPA protocols was used with $Q_{\text {dust/soil }}$ at $0.05 \mathrm{~g}$ per day. ${ }^{22} F_{\text {uptake }}$ represents the uptake fraction of the compound. Due to the lack of directly measured specific $F_{\text {uptake }}$ for siloxane, we used 1.0 as the value for all studied siloxanes.

The inhalation exposure $\left(E_{\text {inhale }}\right)$ was calculated using the following equation:

$$
E_{\text {inhale }}=C_{\text {air }} \times V_{\text {air }} \times F_{\text {uptake }}
$$

where $C_{\text {air }}$ is the concentration of siloxanes in air $\left(\mathrm{ng} / \mathrm{m}^{3}\right)$, and $V_{\text {air }}$ is the volume of inhalation $\left(\mathrm{m}^{3} /\right.$ day; $20 \mathrm{~L} / \mathrm{min}$ for adults). As previous studies indicated that inhalation $F_{\text {uptake }}$ for D4 and D5 was about 0.1 due to their low blood/air partition, ${ }^{16,17}$ our study selected 0.1 as inhalation $F_{\text {uptake }}$ for cyclic compounds (D4-D6). Due to lack of specific $F_{\text {uptake }}$ for linear compounds, 1.0 was selected as $F_{\text {uptake }}$ for L3-L16. However, it should be notable that due to similar properties of vapor pressure and lipophilicity, they (especially for those with smaller number of $\mathrm{Si}-\mathrm{O}$ bones) are likely to have $F_{\text {uptake }}$ similar to cyclic ones (D4 and D5).

SI Table S7 shows the results of human exposure to total cyclic methyl siloxanes ( $\Sigma$ CMSs) and total linear methyl siloxanes ( $\Sigma$ LMSs) in the three zones. Methyl siloxane concentrations in both indoor air and dust from the studied facility (zone A) were about $1-5$ orders of magnitudes higher than those from the reference zone (Zone $\mathrm{C}$ ), indicating that exposure in the facility dominated the total exposure pathway for workers. Furthermore, the time spent in workshop was about $8 \mathrm{~h}$ per day for each worker, and a more reasonable estimation of the occupational exposure for workers would be $1 / 3$ of the calculated values for $E_{\text {ingest }}$ and $E_{\text {inhale }}$ from the indoor exposure. In the six workshops, inhalation dominated the exposure pathway for $\Sigma$ CMSs $(8.92-93.0 \mathrm{mg} / \mathrm{d})$, while those via ingestion $(0.38-7.89 \mu \mathrm{g} / \mathrm{d})$ were about $3-4$ orders of magnitudes lower. $\Sigma$ LMSs intakes via ingestion $(0.12-169 \mu \mathrm{g}$ ) d) were 1-3 orders of magnitudes lower than those via inhalation $(173-752 \mu \mathrm{g} / \mathrm{d})$.

Zone $\mathrm{B}$ is downwind of the studied siloxanes production facility. In the residential community in Zone B, methyl siloxanes were not measured from indoor air or dust samples. However, being affected by the studied facility, cyclic methyl siloxanes concentrations in both outdoor air and soil samples in this zone (sites B3 and B4) were 1-3 orders of magnitudes higher than those in the reference zone (Zone C). It is therefore assumed that evaluation for exposures of $\Sigma \mathrm{CMSs}$ $(7.3-8.9 \mathrm{mg} / \mathrm{d}$ for inhalation, $13-18 \mathrm{ng} / \mathrm{d}$ for ingestion) in Zone B using outdoor concentrations would be appropriate. In contrast to cyclic siloxanes, concentrations of L8, L9, and L16 $(3.2-22 \mathrm{ng} / \mathrm{g})$ in outdoor soil at sites B3 and B4 were comparable or lower than those $(13-58 \mathrm{ng} / \mathrm{g})$ in the reference zone, indicating that linear methyl siloxanes from the production facility only slightly affected the outdoor soil in Zone $\mathrm{B}$. In Zone $\mathrm{C}$, indoor total exposure to cyclic compounds was about $13-32 \mu \mathrm{g} / \mathrm{d}$ via inhalation, while $3.2-4.5 \mathrm{ng} / \mathrm{d}$ via ingestion. Indoor total exposure to linear compounds was 1.0$11.6 \mathrm{ng} / \mathrm{d}$ via ingestion (inhalation was not detected).

In general, human exposures of methyl siloxanes around the siloxanes production facility were $2-3$ orders of magnitudes higher than those in the reference zone, suggesting the importance of inhalation and ingestion to human exposure around siloxanes production facilities.

3.3. Methyl Siloxanes in Plasma Samples of Current Workers and Residents. Figure 3 shows the profile of methyl siloxanes in plasma samples $(n=144)$ of population from the three zones. Among the 58 plasma samples from the reference group, only D4 and D5 of the seventeen compounds were detected in two $(1.2-3.6 \mathrm{ng} / \mathrm{g})$ and three samples (2.0-5.0 $\mathrm{ng} / \mathrm{g}$ ), respectively, indicating that low exposure to methyl siloxanes in the reference group. This result was consistent with a previous study reporting that no methyl siloxane was found in plasma of general public group in Germany. ${ }^{23}$ For the high exposure population in Zone A and B, methyl siloxanes were detected in plasma samples at much higher concentrations and frequencies. Average concentrations of cyclic methyl siloxanes (D4, D5, and D6) in plasma samples of current workers $(n=$ $72)$ were $206(\mathrm{df}=100 \%), 215(\mathrm{df}=100 \%)$, and $88.7 \mathrm{ng} / \mathrm{g}(\mathrm{df}$ $=100 \%$ ), respectively. While all linear compounds (L3-L16), except for L4, were detectable in the 72 samples with average 

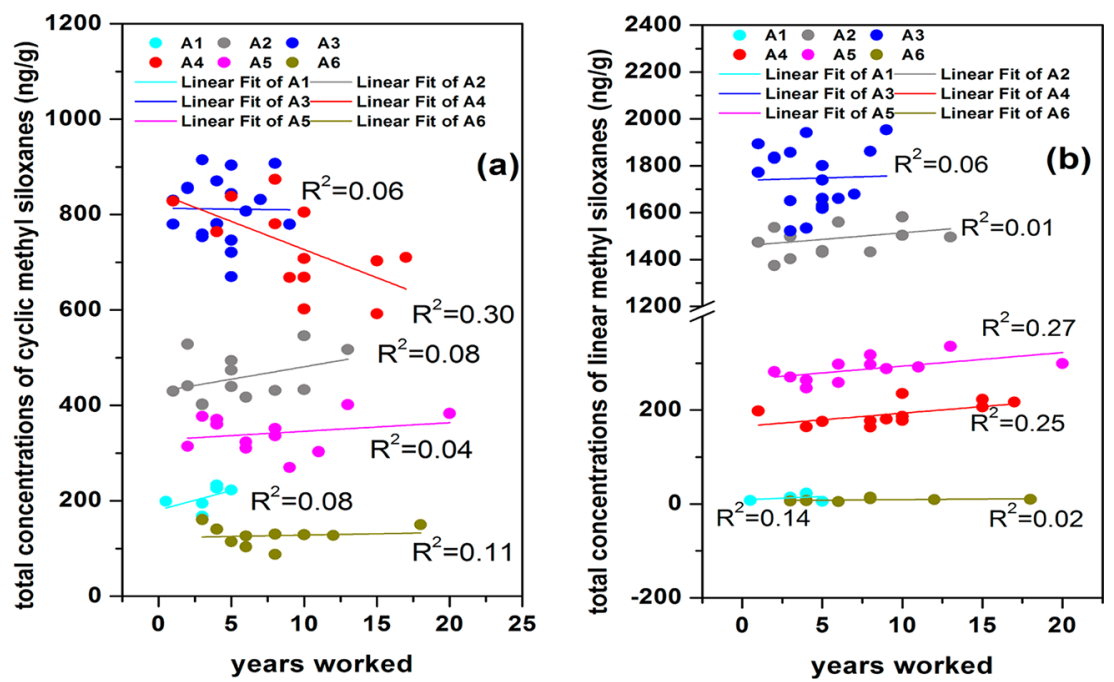

Figure 4. Correlations between total cyclic (a) and linear (b) methyl siloxanes concentrations of plasma samples from current workers in the six workshops (A1-A6) and their years worked.
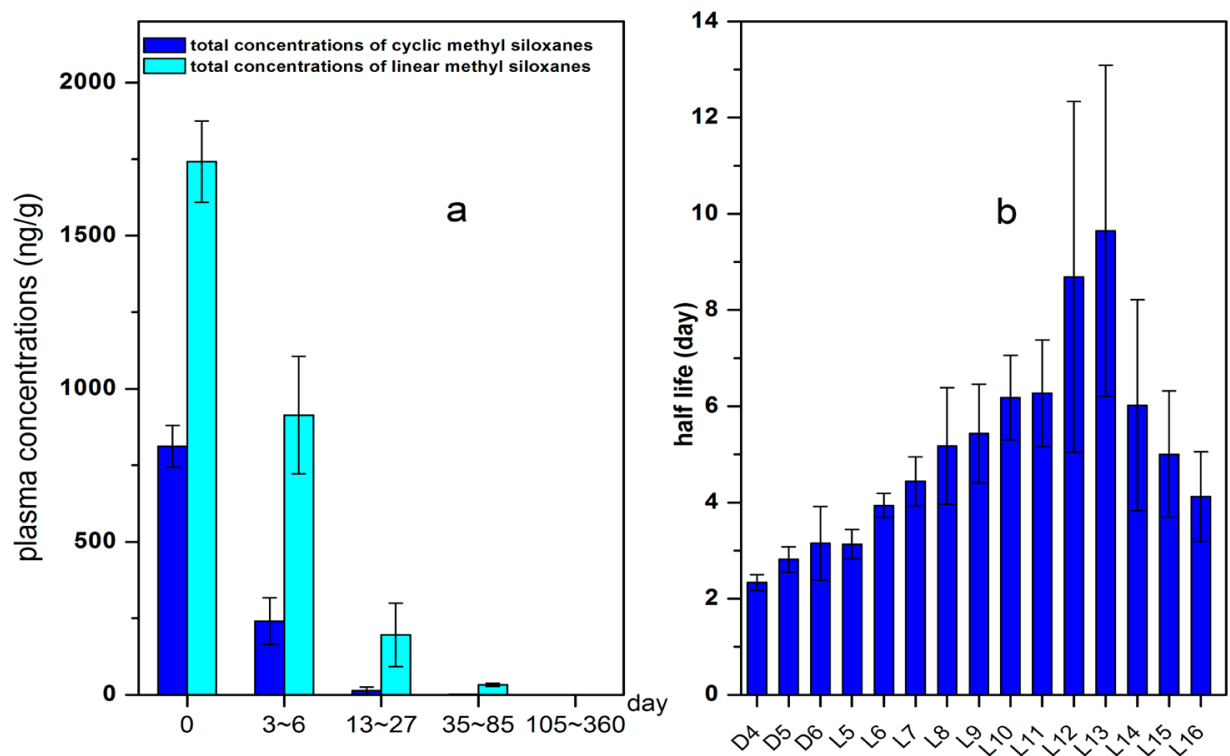

Figure 5. (a) total methyl siloxanes concentrations (average values) of plasma samples provided by current workers $($ days $=0$ ) and former workers (days = 3-360) from A3 workshop and days since they left the facility; (b) half-lives of methyl siloxanes in plasma via longitudinal analysis.

concentrations ranging from 5.62 to $451 \mathrm{ng} / \mathrm{g}$ ( $\mathrm{df}=80.5-$ $100 \%)$. At Zone B, D4, D5, and D6 were detected (36-100\%, detected frequencies) in plasma samples $(n=14)$, with average concentrations of $13.5,57.8$, and $4.56 \mathrm{ng} / \mathrm{g}$, respectively.

Significant and positive correlations $\left(R^{2}=0.90, p<0.05\right)$ were found between total plasma concentrations of cyclic methyl siloxanes and human exposure (daily intake). Similar results were also found for linear compounds $\left(R^{2}=0.93, p<\right.$ $0.05)$. Although there was no other study on methyl siloxanes concentrations in plasma/blood of occupational exposure group, the present study strongly indicated that exposure to methyl siloxanes in high contamination areas (such as around the manufacturing facilities) results in elevated concentrations in human plasma. In addition, personal hygiene practices to control chemical exposure in industry could affect plasma methyl siloxanes concentrations of individuals. According to our survey, the workers in this facility did not use special personal protective gears (such as filter masks and respirators) to limit siloxanes exposure via inhalation and ingestion. In the majority of siloxanes production facilities in P.R. China, other than maintaining ventilation in workshops and wearing gloves and goggles, there are no additional exposure control measures. Our survey of several other sioxanes production facilities showed that most of them had similar operational conditions. Therefore, we believe that the concentrations in human plasma from the studied facility are representative of occupational exposure in siloxanes production facilities in China. We however note that methyl siloxane concentrations in plasma of exposed workers would likely be lower if the siloxanes facilities had more robust measures regulating these exposure.

In each of the six workshops, there was no significant linear correlation between total cyclic (or linear) methyl siloxanes concentrations in plasma samples from current workers and their years worked in the facility (Figure 4). Furthermore, results of the Friedman Test showed that in each of the six workshops, plasma methyl siloxanes concentrations of workers 
with different working years had no significant difference $(p<$ 0.05 ). These results indicated that methyl siloxanes in plasma perhaps have a relatively short time to reaching steady state during exposure. This behavior is different from typical persistent organic pollutants (POPs), such as polyfluorinated compounds (PFCs), ${ }^{24}$ polybrominated diphenyl ethers (PBDEs), ${ }^{25}$ and polycyclic aromatic hydrocarbons (PAHs), ${ }^{25}$ which concentrations in human plasma/blood may increase with exposure time due to limited whole body clearance. ${ }^{26}$

3.4. Elimination of Methyl Siloxanes from Plasma. To investigate the elimination of methyl siloxanes from human plasma, 57 plasma samples were collected from 32 former workers from A3 workshop of the studied production facility at Aug 24 and Oct 2, 2011. These persons had left the facility for 3-320 days with no additional occupational exposure, and did not live in Zone B. Methyl siloxanes were detectable in 32 out of the 57 samples, with concentrations significantly lower than those in samples of current workers from the same workshop ( $p<0.05, t$ test). Generally, the plasma concentrations of both cyclic and linear methyl siloxanes decreased with the increase of days since the worker had left the facility (Figure 5a, SI Table S8). Notably, none of the methyl siloxanes were detectable in plasma samples of former workers who had left the facility for more than 85 days.

The conventional method for estimating the chemical halflife in plasma is by longitudinal analysis of repeated measurements of its plasma concentrations in the same individual. However, due to limited sampling time points (one or two points) for each former worker in our study, the conventional method was not applicable. Therefore, an alternative "population-based" method, used limited sampling time points from each individual, ${ }^{27-30}$ was instead utilized in the present study. Following this method, we treated all former workers as "the same individual", and plotted the concentrations of their plasma samples versus the days since they left the facility (SI Figure S2). This approach was based on several observations: the methyl siloxanes plasma concentrations of exposed population are not correlated with their exposure time, but with their levels of exposure (discussed in section 3.3). During the last three years, there was no change in the siloxanes production process and annual yield in this facility were stable. Therefore, exposure levels of the 32 former workers from A3 during their working time were similar. In addition, if there were significantly interindividual differences, "populationbased" plasma elimination model could be adjusted by individual characteristics (such as race, gender, age, and weight, etc.) using "nonlinear mixed effect approach". ${ }^{27,28}$ In the present study, 32 plasma samples containing detectable methyl siloxanes were obtained from 24 male former workers (SI Table S8), whose characteristics have few interindividual differences (SI Table S9): from the same race; no smoker; without any known significant health problems; similar ages $(\mathrm{RSD} \%=3.7)$, weights (RSD\% = 3.1), Body Mass Indexes (RSD\% = 3.5), and serum total protein $(\mathrm{RSD} \%=2.5)$. Perhaps due to their similar individual characteristics, analysis of nonlinear mixed effect approach showed that none of these characteristics influenced significantly $(P>0.05)$ our first-order elimination model (the model selection was discussed in the following paragraph) for each compound. Therefore, the model was not adjusted by individual characteristics in the present study.

Previous studies have proposed several elimination models of two volatile cyclic methyl siloxanes (D4 and D5) in rats and humans in detail. ${ }^{31-35}$ One report indicated that D4 is eliminated from plasma/blood following a two-compartment model: a fast phase of distribution in fat and tissues followed by a slow elimination phase. ${ }^{31}$ Subsequently, basing on a refined physiologically based pharmacokinetic (PBPK) model, several reports provided a comprehensive elimination model for D4: a fast phase of exhalation of free D4 in blood and tissues, the slower phase of redistribution from tissue stores, and the slowest phase of redistribution from fat. ${ }^{32,33}$ According to these two models mentioned above and another (also basing on PBPK) reported in the ref 35 , we speculated that only an elimination phase (similar to first-order kinetics) for volatile cyclic methyl siloxanes would be observed after 3 days after ending the exposures. Furthermore, there was no report on detailed kinetics of linear methyl siloxanes with larger numbers of Si-O bonds (such as L5-L16) in human plasma, which may have different kinetic characteristics with D4 and D5 due to their lower vapor pressures.

In the present study, "population-based" half-lives of cyclic methyl siloxanes (D4-D6) were in the range of 2.34 (D4) to 3.15 (D6) days $\left(R^{2}=0.86-0.98, p<0.05\right.$, Figure $\left.5 \mathrm{~b}\right)$. The "population-based" half-life of D4 in the present study (2.34 days) was comparable to that in rats $(50-80 \mathrm{~h})$ reported in a previous study, ${ }^{31}$ while about 10 times longer than those in an in vivo exposure study $\left(T_{1 / 2}\right.$ of D4 was about $\left.5.5 \mathrm{~h}\right) .{ }^{16}$ Figure $5 \mathrm{~b}$ showed that "population-based" half-lives of D4, D5, and D6 increased with the increasing number of their $\mathrm{Si}-\mathrm{O}$ bonds. D4 and D5 are eliminated from human plasma mainly by oxidative metabolism in liver and exhalation. ${ }^{32-34}$ Compared with D5, the plasma elimination rate of $\mathrm{D} 4$ via exhalation is slower, but its hepatic metabolism rate is faster, ${ }^{36}$ which are not entirely consistent with our half-lives trend for D4-D6. In the liver, D4/D5 first undergoes oxidation of $-\mathrm{CH}_{3}$ group to $-\mathrm{CH}_{2} \mathrm{OH}$, then rearrangement of $-\mathrm{CH}_{2} \mathrm{OH}$ to $-\mathrm{OH}$ followed by $\mathrm{Si}-\mathrm{O}$ ring-opening, which were sequentially hydrolyzed leading to various linear silanols, such as dimethylsilanediol $\left[\mathrm{Me}_{2} \mathrm{Si}\right.$ $\left.(\mathrm{OH})_{2}\right]$ and methylsilanetriol $\left[\mathrm{MeSi}(\mathrm{OH})_{3}\right]$, etc. ${ }^{33}$ Consistent with previous study, $\mathrm{Me}_{2} \mathrm{Si}(\mathrm{OH})_{2}$ was detectable with concentrations in range of $84-369 \mathrm{ng} / \mathrm{g}(\mathrm{df}=100 \%)$ in plasma samples of current workers, but not in the reference group. In addition, $\mathrm{Me}_{2} \mathrm{Si}(\mathrm{OH})_{2}$ was not detectable in indoor air or dust sample from the facility, indicating $\mathrm{Me}_{2} \mathrm{Si}(\mathrm{OH})_{2}$ in plasma was not from direct intake. (The analytical method for the dimethylsilanediol is given in the SI.)

The "population-based" half-lives of linear methyl siloxanes (L5-L16) ranged 3.13 (L5) to $9.64(\mathrm{~L} 13)$ days $\left(R^{2}=0.72-\right.$ $0.99, p<0.05)$. For these compounds, plasma elimination via exhalation could be weaker than volatile cyclic ones (D4-D6) because their much lower vapor pressure could result in higher blood/air partition. This may explain why half-lives of L5 and L6 were longer than their cyclic counterparts (D5 and D6, Figure $5 \mathrm{~b}$ ). Compared with cyclic ones, plasma elimination of linear methyl siloxanes may be more affected by their distributions in fat and tissues due to low vapor pressure and high lipophilicity. On the basis of physical chemical properties, some differences in clearance among the linears are likely due to expected differences in lipophilicity. With the increasing number of Si-O bonds, fat/blood partition of linear methyl siloxanes increase, which maybe result in an increasing half-life. Fat/blood partition could explain the phenomenon of increasing "population-based" half-lives from L5 to L13. However, decreased "population-based" half-lives from L13 to L16 cannot be explained at present. In addition, the observed population-based elimination of linear methyl siloxanes may be 
associated with not only specific loss from muscle, viscera or fatty tissues but also other mechanisms (such as exhalation and hepatic metabolism). Therefore, further studies that assess key factors-blood/air partitioning, fat/blood partitioning and hepatic metabolism for linear siloxanes, which have not been reported until now-should comprehensively clarify the observed differences in plasma elimination curves of L5-L16 and assess whether the differences of their observed populationbased eliminations can be easily associated with specific loss from muscle, viscera, or fatty tissue. For example, besides lipophilicity, other factors (such as hepatic metabolism rates in liver) might play an important role in their elimination. One linear methyl siloxane (hexamethyldisiloxane, L2) undergoes oxidative metabolism in liver. ${ }^{37}$ L5-L16, as homologues of L2, perhaps undergo the similar pathway. If metabolism rates of linear siloxanes in liver decreased with increasing number of $\mathrm{Si}-\mathrm{O}$ bonds, the half-life trends of L5-L13 could be also explained. Due to the lack of reports on hepatic metabolism rates of linear methyl siloxane analogues, our speculation about their metabolism rates trend could not be proved. However, the trends were consisted with results for the cyclic methyl siloxanes in a previous report, ${ }^{37}$ which showed that the metabolism rate of D4 was faster than that of D5.

Generally, our study showed that the "population-based" half-lives of methyl siloxanes in human plasma are shorter than those of other typical POPs such as PFOS (4.8 years, median), PFOA (3.5 years, median), ${ }^{38}$ and PBDEs (15-94 days, median), ${ }^{39}$ indicating that methyl siloxanes are eliminated from human plasma in a relatively short time. While half-lives of methyl siloxanes are for plasma samples in the present study, fat/tissue accumulation and elimination were not measured. A previous study indicated that due to low blood/air partition and high hepatic clearance, the more volatile cyclic methyl siloxanes (such as D4 and D5) do not accumulate in systemic tissues, because of higher whole body clearance compared to POPs. ${ }^{26}$ However, for linear methyl siloxanes (L5-L16), which have lower vapor pressures and higher lipophilicities, accumulation in fat and tissues may be more substantial than cyclic compounds. Several literatures reported that linear methyl siloxanes can accumulate in fat/tissues of both animal and human. ${ }^{40,41}$ Therefore, future studies should pay more attention to occupational exposure and elimination of linear methyl siloxanes from fat and tissues of the exposed workers.

\section{ASSOCIATED CONTENT}

\section{S Supporting Information}

This information is available free of charge via the Internet at http://pubs.acs.org

\section{AUTHOR INFORMATION}

\section{Corresponding Author}

*Tel: +86 (10) 62849182; fax: 8610-62849182; e-mail: caiyaqi@rcees.ac.cn.

\section{Notes}

The authors declare no competing financial interest.

\section{ACKNOWLEDGMENTS}

This work was supported by the National Natural Science Foundation of China (No. 20837003, 20921063, 20890111) and the National Basic Research Program of China (2009CB421605).

\section{REFERENCES}

(1) Silicones Environmental, Health and Safety Council of North America (SEHSC). Available from: http://www.sehsc.com/d5.asp. 2011

(2) Horii, Y.; Kannan, K. Survey of organosilicones compounds, including cyclic and linear siloxanes, in personal-care and household products. Arch. Environ. Contam. Toxicol. 2008, 55, 701-710.

(3) Lu, Y.; Yuan, T.; Wang, W. H.; Kannan, K. Concentrations and assessment of exposure to siloxanes and synthetic musks in personal care products from China. Environ. Pollut. 2011, 159, 3522-3528.

(4) Warner, N. A.; Evenset, A.; Christensen, G.; Gabrielsen, G. W.; Borgå, K.; Leknes, H. Volatile siloxanes in the European arctic: assessment of sources and spatial distribution. Environ. Sci. Technol. 2010, 44 (19), 7705-7710.

(5) Sanchez-Brunete, C.; Miguel, E.; Albero, B.; Tadeo, A. J. Determination of cyclic and linear siloxanes in soil samples by ultrasonic-assisted extraction and gas chromatography-mass spectrometry. J. Chromatogr. A 2010, 1217 (45), 7024-7030.

(6) Boehmer, T.; Gerhards, R. Decamethylcyclopentasiloxane (D5), A Compilation of Environmental Data. Essen: Degussa Goldschmidt AG; Brussels: Centre Européen des Silicones 2003.

(7) Zhang, Z. F.; Qi, H.; Ren, N. Q.; Li, Y. F.; Gao, D. W.; Kannan, $\mathrm{K}$. Survey of cyclic and linear siloxanes in sediment from the songhua river and in sewage sludge from wastewater treatment plants, northeastern China. Arch. Environ. Contam. Toxicol. 2011, 60, 204211.

(8) Kierkegaard, A.; Egmond, R. V.; Mclachlan, M. S. Cyclic volatile methylsiloxane bioaccumulation in flounder and ragworm in the Humer Esturary. Environ. Sci. Technol. 2011, 45, 5936-5942.

(9) Liebierman, M. W.; Lykissa, E. D.; Barrios, R.; Qu, C. N.; Kala, G.; Kala, S. V. Cyclosiloxanes produce fatal liver and lung damage in mice. Environ. Health Perspect. 1999, 107, 161-165.

(10) He, B.; Rhodes-Brower, S.; Miller, M. R. Octamethylcyclotetrasiloxane exhibits estrogenic activity in mice via ER alpha. Toxicol. Appl. Pharmacol. 2003, 192, 254-261.

(11) OEHHA. Toxicity data review: Decamethylcyclopentasiloxane (D5). Available from: http://www.arb.ca.gov/toxics/dryclean/ oehhad5review.pdf. 2007.

(12) Brooke, D. N., Crookes, M. J., Gray, D., Robertson, S. Environmental Risk Assessment Report: Decamethylcyclopentasiloxane; Environment Agency of England and Wales: Bristol, 2009.

(13) Brooke, D. N., Crookes, M. J., Gray, D., Robertson, S. Environmental Risk Assessment Report: Octamethylcyclotetrasiloxane; Environment Agency of England and Wales: Bristol, 2009.

(14) Shields, H.; Fleisher, D. M.; Weschler, C. J. Comparisons among VOCs measured in three types of U.S. commercial buildings with different occupant densities. Indoor Air 1996, 6, 2-17.

(15) Kaj, L., Andersson, J., Palm Cousins, A., Schmidbauer, N., Brorström-Lundén, E. Results from the Swedish National Screening Programme 2004, Subreport 4: Siloxanes; IVL: Stockholm, 2005.

(16) Utell, M. J.; Gelein, R.; Yu, C. P.; Kenaga, C.; Geigel, E.; Torres, A.; Chalupa, D.; Gibb, F. R.; Speers, D. M.; Mast, R. W.; Morrow, P. E. Quantitative exposure of humans to an octamethylcyclotetrasiloxane (D4) vapor. Toxicol. Sci. 1998, 44, 206-213.

(17) Reddy, M. B.; Dobrev, I. D.; McNett, D. A.; Tobin, J. M.; Utell, M. J.; Morrow, P. E.; Domoradzki, J. Y.; Plotzke, K. P.; Andersen, M. E. Inhalation dosimetry modeling with decamethylcyclopentasiloxane in rats and humans. Toxicol. Sci. 2008, 105 (2), 275-285.

(18) Mclachlan, M. S.; Kierkegaard, A.; Hansen, K. M.; Egmond, R. V.; Christensen, J. H.; Skjøth, C. A. Concentrations and fate of decamethylcyclopentasiloxane (D5) in the atmosphere. Environ. Sci. Technol. 2010, 44 (14), 5365-5370.

(19) Kaj, L., Schlabach, M., Andersson, J., Palm Cousins, A., Schmidbauer, N., Brorström-Lundén, E. Siloxanes in the Nordic Environment; Nordic Council of Ministers: Copenhagen, 2005.

(20) Kochetkov, A.; Smith, J. S.; Ravikrishna, R.; Valsaraj, K. T.; Thibodeaux, L. J. Air-water partition constants for volatile methyl siloxanes. Environ. Toxicol. Chem. 2001, 20 (10), 2184-2188. 
(21) Lu, Y.; Yuan, T.; Yun, S. H.; Wang, W. H.; Wu, Q.; Kannan, K. Occurrence of cyclic and linear siloxanes in indoor dust from China, and implications for human exposures. Environ. Sci. Technol. 2010, 44, 6081-6087.

(22) Abdallah, M. A. E.; Harrad, S. Personal exposure to HBCDs and its degradation products via ingestion of indoor dust. Environ. Int. 2009, 35, 870-876.

(23) Flassbeck, D.; Pfleiderer, B.; Grümping, R.; Hirner, A. V. Determination of low molecular weight silicones in plasma and blood of women after exposure to silicone breast implants by GC/MS. Anal. Chem. 2001, 73, 606-611.

(24) Liu, J. Y.; Li, J. G.; Luan, Y.; Zhao, Y. F.; Wu, Y. N. Geographical distribution of perfluorinated compounds in human blood from Liaoning Province, China. Environ. Sci. Technol. 2009, 43, 4044-4048.

(25) Qin, Y. Y.; Leung, C. K. M.; Lin, C. K.; Leung, A. O. W.; Wang, H. S.; Giesy, J. P.; Wong, M. H. Halogenated POPs and PAHs in blood plasma of Hong Kong residents. Environ. Sci. Technol. 2011, 45, 1630-1637.

(26) Andersen, M. E.; Reddy, M. B.; Plotzke, K. P. Are highly lipophilic volatile organic compounds expected to bioaccumulate on repeated exposures? Toxicol. Ltrs. 2008, 179, 85-92.

(27) Seals, R; Bartell, S. M.; Steenland, K. Accumulation and clearance of perfluorooctanoic acid (PFOA) in current and former residents of an exposed community. Environ. Health Perspect. 2011, 119 (1), 119-124.

(28) Stahlhut, R.; Welshons, W.; Swan, S.; Bisphenol, A. Bisphenol A data in NHANES suggest longer than expected half-life, substantial nonfood exposure, or both. Environ Health Perspect. 2009, 117, 784789.

(29) Haskell, M. J.; Lembcke, J. L.; Salazar, M.; Green, M. H.; Peerson, J. M.; Brown, K. H. Population-based plasma kinetics of an oral dose of $[2 \mathrm{H} 4]$ retinyl acetate among preschool-aged, Peruvian children1-3. Am. J. Clin. Nutr. 2003, 77 (3), 681-686.

(30) Karlsson, M. O.; Molnar, V.; Freijs, A.; Nygren, P.; Bergh, J.; Larsson, R. Pharmacokinetic models for the saturable distribution of paclitaxel. Drug Metab. Dispos. 1999, 27 (10), 1220-1223.

(31) Meeks, R. The Dow Corning Siloxane Research Program: An overview and update. Med. Dev. Diag. Ind. 1999, 20, 112. Available at: www.mddionline.com/article/dow-corning-siloxane-research-programoverview-and-update

(32) Reddy, M. B.; Dobrev, I. D.; Plotzke, K. P.; Andersen, M. E.; Reitz, R. H.; Morrow, P.; Utell, M. A physiologically based pharmacokinetic model for inhalation of octamethylcyclotetrasiloxane (D4) in human during rest and exercise. Toxicol. Sci. 2003, 72, 3-18.

(33) Andersen, M. E.; Sarangapani, R.; Reitz, R. H.; Gallavan, R. H.; Doberv, I. D.; Plotzke, K. P. Physiological modeling reveals novel pharmacokinetic behavior for inhaled octamethylcyclotetrasiloxane in rats. Toxicol. Sci. 2001, 60, 214-231.

(34) Reddy, M. B.; Dobrev, I. D.; McNett, D. A.; Tobin, J. M.; Utell, M. J.; Morrow, P. E.; Domoradzki, J. Y.; Plotzke, K. P.; Andersen, M. E. Inhalation dosimetry modeling with decamethylcyclopentasiloxane in rats and humans. Toxicol. Sci. 2008, 105 (2), 275-285.

(35) Luu, H. M. D.; Hutter, J. C. Bioavailability of octamethylcyclotetrasiloxane (D4) after exposure to silicones by inhalation and implantation. Environ Health Perspect. 2011, 109 (11), 1095-1102.

(36) Reddy, M. B.; Looney, R. J.; Utell, M. J.; Plotzke, K. P.; Andersen, M. E. Modeling of human dermal absorption of octamethylcyclotetrasiloxane (D4) and decamethylcyclopentasiloxane (D5). Toxicol. Sci. 2007, 99 (2), 422-431.

(37) Varaprath, S.; Mcmahon, J. M.; Plotzke, K. P. Metabolites of hexamethyldisiloxane and decamethylcyclopentasiloxane in fischer 344 rat urine-a comparison of a linear and a cyclic siloxane. Drug Metab. Dispos. 2003, 31 (2), 206-214.

(38) Olsen, G. W.; Burris, J. M.; Ehresman, D. J.; Froehlich, J. W.; Seacat, A. M.; Butenhoff, J. L.; Zobel, L. R. Half-life of serum elimination of perfluorooctanesulfonate, perfluorohexanesulfonate, and perfluorooctanoate in retired fluorochemical production workers. Environ. Health Perspect. 2007, 115 (9), 1298-1304.
(39) Thuresson, K.; Höglund, P.; Hagmar, L.; Siödin, A.; Bergman, A.; Jakobsson, K. Apparent half-lives of hepta- to decabrominated diphenyl ethers in human serum as determined in occupationally exposed workers. Environ. Health Perspect. 2006, 114 (2), 176-181.

(40) Flassbeck, D.; Pfleiderer, B.; Klemens, P.; Heumann, K. G.; Eltze, E.; Hirner, A. V. Determination of siloxanes, silicon, and platinum in tissues of women with silicone gel-filled implants. Anal. Bioanal. Chem. 2003, 375, 356-362.

(41) Kala, S. V.; Lykissa, E. D.; Neely, M. W.; Lieberman, M. W. Low molecular weight silicones are widely distributed after a single subcutaneous injection in mice. Am. J. Pathol. 1998, 152 (3), 645-649. 